\title{
Chemical and glass thermometers for axillary temperatures: how do they compare?
}

Departments of
Medicine and Nursing
Queen Elizabeth
Hospital for Children,
London
D Payne
A Johnson
S McKenzie
M Rogers
Correspondence to:
Dr S McKenzie, Queen
Elizabeth Hospital for
Children, Hackney Road,
London E2 9PS.
Accepted 16 May 1994

\author{
Donald Payne, Alice Johnson, Sheila McKenzie, Maggie Rogers
}

\begin{abstract}
Axillary temperatures recorded with a disposable chemical thermometer (DCT) measured a mean $0.29^{\circ} \mathrm{C}$ higher than a mercury in glass thermometer (MGT) but differences could be wide. Differences between the same methods were however also wide. The DCT is safe and easy to use. Provided the higher readings are taken into consideration it is a suitable alternative to the MGT.

(Arch Dis Child 1994; 71: 259-260)
\end{abstract}

In many paediatric units the axilla is still the preferred site for temperature recording, although it is well known that temperatures taken with the electronic thermometer and with the mercury in glass thermometer (MGT) in this site are poor predictors of fever. ${ }^{12}$ There has been concern about the fragility of the $\mathrm{MGT}^{3}$ and the risk of cross infection, especially when the temperature is recorded in the rectum. This has encouraged the development of a disposable plastic strip chemical thermometer (DCT) (Tempa.DOT, PyMah Corporation; figure). The colour of each 'dot' changes with each $0 \cdot 1^{\circ} \mathrm{C}$. This thermometer is in use in $5 \%$ of hospitals in the UK and $15 \%$ of hospitals in the USA (personal communication). It has replaced the MGT in all departments of the Hospitals for Sick Children, London. Previous work using this method has suggested that axillary temperatures within what is generally accepted to be the normal range agree poorly with those recorded using the MGT. 4

Although new house officers and others unfamiliar with the DCT understood the merit of a disposable and safe thermometer, they felt confused by its readings which often seemed unexpectedly high. The purpose of this study was to discover how well readings with the DCT and MGT agreed over a range of axillary temperatures which included readings above $38^{\circ} \mathrm{C}$. Such readings may prompt investiga-

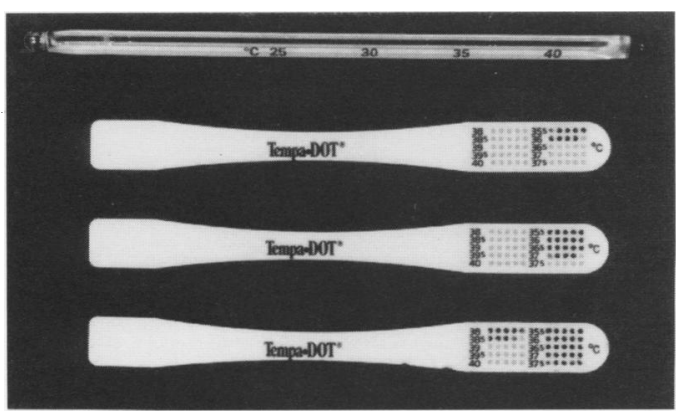

DCTs showing different temperatures. An MGT is shown to compare size. tions for infection, and in some patients, such as those who are neutropenic, might be used as criteria for starting antimicrobial treatment. Fever in patients receiving blood transfusions suggests a transfusion reaction. In all of these patients the understanding of temperature recordings is important.

A second purpose of the study was to compare temperatures taken by the same method in both axillas using two MGTs and two DCTs. If readings are identical this would suggest that not only are the temperatures in the axillae the same but also the method of thermometer placement is satisfactory. If readings are not identical then either the skin temperatures of the axillae are truly different, or the method of measuring is unsatisfactory. The DCT is smaller, more flexible, and easier to position than the MGT because it adheres to the axillary wall. We wanted to know whether the DCT gave more consistent readings in the axilla than the MGT and would therefore be a more reliable reflector of core temperature and thus a better predictor of fever.

\section{Methods}

Simultaneous measurements were made on children up to age 16 years attending the hospital. An MGT was left in the axilla for five minutes and a DCT for three minutes, as recommended by the manufacturers. Several readings from the same child were included provided they were recorded no more frequently than clinically indicated.

Using the method of Bland and Altman the means of the pairs of readings were grouped as follows: group $135^{\circ} \mathrm{C}-36.95^{\circ} \mathrm{C}$, group 2 $37^{\circ} \mathrm{C}-37.95^{\circ} \mathrm{C}$, group $338^{\circ} \mathrm{C}-41.5^{\circ} \mathrm{C}$ and the differences between MGT and DCT were calculated. ${ }^{5}$ The mean differences were calculated for the whole group and for each subgroup.

Simultaneous measurements were made with an MGT in each axilla and with a DCT in each axilla. The mean (SD) difference between the pairs of measurements was calculated.

\section{Results}

The DCT read higher than the MGT in all groups (table). The simultaneous readings with the MGT and DGT are also shown in the table.

\section{Discussion}

The three ranges we chose for comparison of readings with DCTs and MGTs correspond 
Readings from the two parts of the study

\begin{tabular}{|c|c|c|c|c|}
\hline & No & $\begin{array}{l}\text { Mean } \\
\text { difference } \\
\left({ }^{\circ} \mathrm{C}\right)\end{array}$ & $\begin{array}{l}\text { 95\% Confidence } \\
\text { interval }\end{array}$ & $2 S D$ \\
\hline $\begin{array}{l}\text { All pairs } \\
\text { Group 1 } \\
\text { Group } 2 \\
\text { Group } 3\end{array}$ & $\begin{array}{r}281 \\
134 \\
77 \\
70\end{array}$ & $\begin{array}{l}0.29 \\
0 \cdot 23 \\
0 \cdot 36 \\
0 \cdot 32\end{array}$ & $\begin{array}{l}0.25 \text { to } 0.33 \\
0.19 \text { to } 0.27 \\
0.30 \text { to } 0.42 \\
0.23 \text { to } 0.41\end{array}$ & $\begin{array}{l}0.62 \\
0.56 \\
0.54 \\
0.76\end{array}$ \\
\hline $\begin{array}{l}\text { MGT } \\
\text { DCT }\end{array}$ & $\begin{array}{l}62 \\
62\end{array}$ & $\begin{array}{r}0.007 \\
-0.023\end{array}$ & $\begin{array}{l}-0.013 \text { to } 0.017 \\
-0.123 \text { to } 0.077\end{array}$ & $\begin{array}{l}0.74 \\
0.76\end{array}$ \\
\hline
\end{tabular}

Comparison of the differences in groups 2 and 3 with group 1 using unpaired $t$ testing gave $p$ values of 0.0025 and 0.0559 respectively.

broadly to those considered to represent normal temperatures (group 1), low grade fever (group 2), and significant fever (group 3 ). The DCT recorded a mean of $0.29^{\circ} \mathrm{C}$ higher in the group as a whole. Perhaps this is because the DCT is designed to record temperature on the side of the axilla closest to the vessels of the chest wall whereas the bulb of the MGT, being round, records from all sides of the axilla. If this is the reason the DCT readings appear to be closer to core temperatures. The mean differences in groups 2 and 3 are larger than group 1. This is not an unexpected finding as the magnitude of the measurements increases. There is also a wider range of differences especially in group 3, the group which represented significant fever.

It is not the purpose of this communication to advocate the use of any particular site of temperature recording, as debate about this topic has been covered elsewhere. ${ }^{12}$ Our purpose is to alert those who are unfamiliar with the DCT to the higher readings that it records when compared with the MGT when temperatures are recorded in the axilla. Temperature charts in many hospitals have a thick line drawn across the page at a reading, either $36.8^{\circ} \mathrm{C}$ or $37^{\circ} \mathrm{C}$. This is often understood to divide normal from raised temperature readings. Perhaps the need for such a line should be reconsidered as the interpretation of temperature readings is, among many things, dependent on the instrument and site of recording. Many services have drawn up guidelines for conditions, such as those where a patient is immunocompromised, where fever is an important criterion for starting investigation and treatment. If the DCT is to be used for this purpose then guidelines that assume MGT readings will need to take this into account. Otherwise investigations and management, often with expensive antimicrobial drugs, could be implemented unnecessarily.

Our second purpose is to draw attention to the differences between simultaneous measurements of axillary temperatures with both methods. These could be substantial irrespective of instrument. Presumably the higher temperature is closer to the core temperature. In the group we have tested, the DCT is no more likely to give consistent readings than the MGT in the axilla and by inference therefore is neither better nor worse at predicting fever. As it is undoubtedly safer and easier to use ${ }^{4}$ we would recommend it as a suitable replacement for the MGT.

1 Morley CJ, Hewson PH, Thornton AJ, et al. Axillary and rectal temperature measurements in infants. Arch Dis Child 1992; 67: 122-5.

2 Kresch MJ. Axillary temperature as a screening test for feve in children. $\mathcal{F}$ Pediatr 1984; 104: 596-9.

3 Blumenthal I. For debate - should we ban the mercury thermometer? $\mathcal{f} R$ Soc Med 1992; 85: 553-5.

4 Rogers $M$. A viable alternative to the glass/mercury thermometer. Paediatric Nursing 1992; 4: 8-11.

5 Bland JM, Altman D. Statistical methods for assessing agreement between two methods of clinical measurement. Lancet 1986; i: 307-10. 